\title{
Autism Spectrum Disorder (ASD); Symptoms, Causes, Diagnosis, Intervention, and Counseling Needs of the Families in Jordan
}

\author{
Emad Mohammad ali ${ }^{1}$, Fatimah eid ziad Al- Adwan ${ }^{1} \&$ Yazan M. Al-Naimat ${ }^{1}$ \\ ${ }^{1}$ Educational Sciences Faculty, The University of Jordan, Amman, Jordan \\ Correspondence: Fatimah Al- Adwan, Educational Sciences Faculty, The University of Jordan, Amman, Jordan. \\ E-mail: hu_ss_am@yahoo.com
}

Received: November 1, 2018

Accepted: January 20, 2019

Online Published: April 30, 2019

doi:10.5539/mas.v13n5p48

URL: https://doi.org/10.5539/mas.v13n5p48

\begin{abstract}
Autism Spectrum Disorder (ASD) is one of the most confusing disorders for which not only no exact cause has been identified, but also no definitive cure has been found yet. Autism is a disorder that is usually observed on the child at an early age, affecting various developmental aspects. Its development is abnormal. It shows an imbalance in its social interaction, characterized by repetition of certain behavioral patterns and challenges in verbal and nonverbal communication with others. Over the last few decades, its prevalence showed a dramatic rise; an observation that encouraged many researchers across the globe to try to explore all its aspects from etiology to diagnosis and intervention. Because of the difficulties in teaching children with autism, the families in Jordan encounter many challenges and stresses. This paper discusses the Autism Spectrum Disorder (ASD); Symptoms, Causes, Diagnosis, treatment, types and the counseling needs of the families in Jordan.
\end{abstract}

Keywords: autism spectrum disorder, counseling needs, diagnosis

\section{Introduction}

Citizenship is defined as the status of the citizen who belongs to the homeland and his or her affiliation entails obligations such as loyalty, defense and performance of labor, and entitles him to rights such as the right to education, care and work. Accordingly, citizenship is a strict relationship with a constitution and laws that binds the individual and his state, Between citizens, coexistence, and the democratic system. Often the most straightforward questions reflect both the the most complex questions, the lessons of the most striking news and the problems the most fundamental. How to develop citizenship? is one of them. She returns implicitly to the coherence of a solution, such as these practical manuals entitled to work efficiently? Or "how to cure her plants?" But precisely, it is not certainty that citizenship can be approached this way, despite its apparent homogeneity and unanimity that seems to surround its social and political value.

Autism is a disorder of social development that affects the development of the brain, and hence the behavior of a person. Autistic people live in their own world. This is a generalized developmental disorder of the so-called autistic spectrum observed for the first time by American psychiatrist leo Kanner (Kanner, 1943). In parallel with Kanner, Austrian pediatrician Asperger (1944) observed similar autism clinical symptoms that underlie the Asperger syndrome - another autism spectrum disorder. Autism is often accompanied by extreme behavioral challenges. Autism is diagnosed by observing the deficiencies in behavior in three areas that are the social interaction, communicative ability and the range of activity and interests, which is limited [1].

Some children may appear somewhat different as they develop, either because they avoid eye contact or conversations with their parents or other individuals, demonstrate a particular obsession with certain objects, or become withdrawn and uninterested to social interaction. Well, it is likely that they suffer from infantile autism, a quite common disorder, and that affects their adolescence and even in adulthood. Autism Spectrum Disorders are defined as a set of disorders that affect neurological development [2].

The word "Spectrum" refers to a series of syndromes and stages of detriment that can be experienced by children with autism. The Autism Spectrum range in children from mild to severe symptoms, with many of children with Autism diagnosed with intellectual disabilities [3]. Although the main characteristic of autism is a syndrome that affects social interaction and communication in many of its manifestations, other traits are also associated, among which we can mention behavioral problems, anxiety, depression, disorders in sleeping. Also, other disorders could 
be accompanied such as eating and hyperactive disorders. Additionally, the autistic child usually shows a significant delay in language acquisition, uses words inappropriately and without communicative coherence. If your child loses attention easily, you may have to read our article about attention deficit disorder [4].

Due to the diverse signs and symptoms of autism from one child to another, each of two different children, with the same medical diagnosis, is likely to behave in very different ways and have different skills. However, severe symptoms of autism are characterized, by the total absence to communicate or to establish reciprocal relationships with other people [5]. The symptoms of autism appear in most children in infancy, while other children may develop and develop quite naturally during the first months or years of their lives, but they suddenly lose the language skills they have acquired up until that moment [6].

\section{Symptoms}

\section{Symptoms of Autism}

The autism spectrum syndrome manifests itself in many ways; we can mention the following observable symptoms in the child's behavior [7]:

- He will always seek to isolate himself from the people around him.

- He will not have a conversation with children in his age and, worse still, it will cost him too much to make friends and if he does he have difficulties trying to keep friendships.

- They present difficulties to interpret the emotional situations of the people around them, as well as their feelings. The child with autism may have difficulties to understand facial expressions, gestures and different tones of voice. Additionally, a symptom of autism is that these people do not focus their attention on the face of others and, therefore, are not able to see and learn the appropriate behavioral patterns.

- They have difficulties in verbal and non-verbal communication. Some individuals fail to develop any kind of language.

- Another symptom of autism in children is that they do not share enough with their parents and they will not look for comfort in them, they will not show emotional feedback and they will not share much time with other people.

- Sometimes, the autistic child calls himself in the third person, by his own name, instead in the first person with "me" or "my", this represents an incapacity for self-recognition.

The behavior in the child with autism is of the utmost importance because he will seek to carry out repetitive activities that involve a routine, and frequently presents a limited record of behaviors. An example is that they could align all the toys over and over again, but without playing voluntarily and freely where they display their creativity [7].

It can be noticed that its behavior can vary easily; it is also very sensitive to certain noises and will have periods of hyperactivity. It is essential that parents know what routines the child likes to follow and if parents think to modify or change, it is advisable that the change is not abrupt because this can cause an outbreak of desperation or anger [8].

2.1 The Three Main Symptoms According to Classifications of Mental Illnesses ICD-10 And DSM-IV Are [9]:

1) A violation of social relationships.

2) Speech and language disorders, and

3) A stereotyped, repetitive repertoire of actions and interests.

\subsection{The Violation of Social Relationships}

- Inability to manage their social contacts through non-verbal behavior (social smile, mimic, eye contact)

- Inability to establish relationships with peers (strong lack of interest in peers, lack of friendship)

- Non-sharing of feelings with others (does not mention her or his feelings to others)

- Lack of social-emotional attachment to others (inappropriate behavior in social situations, lack of emotional responses, such as comfort, looks as if they are using others as objects)

\subsection{Violations of Speech and Language}

- Speech is missing or incomprehensible to others

- Lack of compensation of verbal speech through mimic or gestures, lack of spontaneous imitation of the 
actions of others

- Stereotypical, repetitive actions, as well as echolalia, speaking of thoughts aloud.

2.4 Repetitive, Stereotypical Actions are

- Stereotypical, unusual actions or narrowly restricted special interests (rituals, fixed observation of moving objects)

- Stereotypical and repetitive actions (rotation of the fingers in front of the eyes, rocking on a chair, bouncing)

- Occupation with parts of objects or non-functional elements of objects (such as wheelchairs, doll eyes) or unusual interest in aspects of the senses: fixation to a certain smell, taste, touch

\section{Diagnosis of Autism}

To diagnose autism in early age, it is necessary to go through a two-stage process. The first one has to do with an evaluation in all development of the child by a specialist in pediatrics. If this evaluation shows any concern in the development of the child, then it must undergo an additional examination [10].

The second stage encompasses a much more in-depth evaluation, carried out by professionals in the health area with experience in various specialties. During this period, the child may be qualified as having autism spectrum disorder (ASD) or any other disorder associated with development. In general terms, it is possible that an accurate diagnosis can be offered to a child with autism spectrum disorder at two years of age, although it has also been proposed to perform certain evaluations for the detection of this disorder at 18 months after birth [11]. According to the diagnostic classifications of psychiatric disorders, the symptoms of autism must occur before the age of three, but early diagnosis is difficult because symptoms during the first two years are non-specific [12].

As with most of the diagnosis of mental disorders, multidimensional and multimodal diagnosis is needed. The Autism Diagnostic Interview-Revised (ADI-R; Lord, Rutter \& LeCouteur, 1994), and the Autism Diagnostic Observation Schedule (ADOS: Lord et al., 2000) are used as a standard tool for the diagnosis of autism [13]. Additional data is collected by parental and nursing inquiries, neurological examinations (for example, epilepsy can be accompanied with autism in some children with autism) as well as intelligence tests, motor function development, speech and communication, perceptual functions. Multidimensional diagnosis is required on the one hand to identify resources and deficits and, therefore, more successful intervention, on the other, for precise differential diagnosis [14].

\section{Differential Diagnostics}

Autism Spectrum Disorders includes many other disorders. Distinction from other generalized developmental disorders, such as Rett Syndrome and the disintegrative developmental disorder, is relatively easy for the diagnosis [15].

Problem is the distinction between so-called high functioning autism (Fitzgerald \& Colvin, 2001): individual studies discuss that in Asperger the development of speech is the normal, while in high-functioning autism it is not. Also, in Asperger, verbal abilities are better developed than non-verbal abilities [16]. The fact is that there is no clinical tool to distinguish the two disorders and that individuals with high-functioning autism and Asperger, but not with low-functioning autism (below 70 in intelligence scale) in the same families (Szatmari, Jones, Zwaigenbaum \& McLean, 1998). It's said that Asperger and high-functioning autism represent the same disorder in the "normal" field of intellectual functioning. In case of doubt, Asperger's diagnosis is preferable than autism disorder because of the negative nuance of the term autism disorder [17].

Dealing with schizophrenia in childhood is not easy. The main signs of differentiation are as follows: child schizophrenia usually begins suddenly, and a period of development in the norm can be determined before the onset of the disorder, while autism is more constant. There is also a positive symptom in schizophrenia, which is expressed in delusions and hallucinations that are absent in autism. Another distinctive feature relates to non-verbal communication, which is absent or impaired in autism, and which, in schizophrenia, is within the limits of the norm (Volkmar, 1998). Dealing with schizophrenia is important because of medication: prescribed medicines to treat schizophrenia may worsen the symptoms of stereotypical recurrent actions. Kanner's understanding of autism as a schizophrenic disorder (he calls autism "infantile schizophrenia") is not relevant: studies show a missing family relationship between autism and schizophrenia (Fombonne, 2003a). For this reason, autism has been removed from the category of "schizophrenia spectrum disorders" in the current diagnostic classifications and has been introduced as a separate generalized developmental disorder. In some cases, however, a double diagnosis of autism and schizophrenia in childhood is possible [18][19]. 


\section{Causes of Autism}

Although the exact causes of autistic spectrum disorder (ASD) are unknown, some research suggests that both genetics and the environmental factor play a major role in the development of this disorder.

With respect to genetic factors, it has been shown that in [9] out of [10] cases, if one of the identical twin is diagnosed with autism and has the same genetic code as the other one, the latter also develops this condition.

Also, the fact that a brother is diagnosed with autism spectrum disorder increases by $35 \%$ the likelihood that the rest of the siblings many be diagnosed with autism [20]. However, science has not been able to determine exactly which genes are involved in this type of situation. A large percentage of people with autism spectrum disorder have not reported family reports in which autism occurs, so it is likely that the person at risk may be affected by certain circumstantial and scarcely common genetic mutations. It is important to understand that a mutation corresponds to any alteration of the normal genetic code, which may be hereditary or present without any particular reason, and which may be advantageous, harmful or simply not generate any effect [21].

The fact that a child has a greater genetic risk is not synonymous with the fact that he will be diagnosed by Autism certainly. Some scientists and scholars of the field base their research on the interaction that takes place between several groups of genes, as well as on environmental causes, in order to understand more easily how these factors increase the risk of causing autism in children [22].

However, to analyze the environmental factors associated with this disorder, it is pertinent to start from the exact definition of the word "environment". In the field of medicine, the environment is everything that is outside the human body and that has the ability to alter their health. In this way, air, water, food and even medicines are considered part of that "environment" [23]. Also, when human beings are in the womb of our mother, the environment is everything that surrounds us inside your uterus [24]. Some scientists have focused on the analysis of certain environmental factors such as the age of the parents, family medical history, and exposure to toxic substances in pregnancy and complications that may have occurred during the same or at the time of delivery [25]. It is very likely that there is more than one factor involved in the increased risk of autism. However, many people who have been subjected to environmental risk factors have not shown signs of developing autism spectrum disorder [26].

\section{Interventions}

With regard to the intervention, until now, no medication has been found that allows the cure of any of the autistic spectrum disorders. However, there are many therapies aimed at improving the quality of life of those children with autism [27]:

- Behavioral therapy: is also known as the method of Lovaas, ABA or Skinner and is based on behaviorism, encouraging the development of skills in the child through the reinforcement and punishment system.

- Teacch Method: Focuses on communication through images that constitute concepts and has been used in some special education centers in Texas and Missouri.

- $\quad$ PECS (Picture Exchange Communication System): It is a learning strategy through visual elements, reading and writing, whose application has been quite successful in states of the American states and other countries.

- Chemical / Drug: It consists of the intervention of autism in early ages through medications. Although it has been discussed for a long time, it cannot be denied that certain children with autism need drugs because of some dysfunction. Either way, medications should not be given unless you have a prescription.

- Diet without gluten and casein: With this treatment the child is deprived of the consumption of foods rich in gluten and casein, which are part of some products such as wheat flour and dairy. This diet does not generate side effects, so, although it is effective in very few cases, it is still considered as a possible alternative.

- Vitamins: Involves providing the child with a series of vitamins to cover the deficiency of some of them. Studies have corroborated that some children with autism in children lack vitamins such as those of the B complex.

- Method Tomatis and Berard: It consists of teaching the child auditory, managing to open some channels in his brain. This method can be applied in those cases in which the child shows great sensitivity to sound.

- Music therapy: This treatment seeks to train the child through music and rhythm, and has proven to be effective in certain cases.

- Dolphin therapy, equine therapy: Animal therapies such as dolphins and horses are always an option, since they can improve the symptoms of autistic spectrum disorder in children, as well as provide a very pleasant 
experience.

- Another intervention has to do with the development of his verbal ability whose objective is the development of linguistic ability; this activity is usually carried out accompanied by their family environment (parents, siblings, etc.) in order to provide support to them in the development of daily life language for a person with autism.

\section{Recommendations to Help a Child with Autism}

- It has been found that the application of intensive behavioral therapy at an early age can greatly improve cognitive and language abilities in young children with autism spectrum disorder.

- Although there is no single treatment that is effective for all children with autism, the American Academy of Pediatrics has highlighted the essential aspects of some effective programs for early intervention of this disorder, which involve [28]:

- Start treatment as soon as the child has been diagnosed with ASD, encouraging their learning through specific but challenging activities that are appropriate to the child's level of development. The fulfillment of these activities should be encouraged throughout the year and for a minimum of 25 hours per week.

- Teach small classes in which the child has an individual time with the expert or therapist, and promote activities for training in small groups.

- Provide personal instruction to both parents and family members.

- Encourage the development of activities involving children without ASD, as long as they are aimed at achieving a specific goal in children with autism.

- Follow up each child to evaluate their progress and modify the program if necessary.

- Offer routines and sensory aids to reduce distractions.

- Orient the child to put into practice the skills learned in different situations.

Children suffering from child autism are different from the rest of the children and therefore require special treatment. Be patient and look for ways to help them overcome the different disabilities that this condition implies, they need it [29]. The family, or in this case the parents, should help their children and understand them at all times, in the beginning it is a strong process where the strength and commitment of mom and dad is needed. The first steps to help him are: detecting the disorder early, this by observing the child's behaviors; later when it is suspected of suffering from this functional limitation, a specialist must be taken who will perform an examination and then the diagnosis will be given. An essential requirement after the father knows that his son suffers from this behavior disorder is to offer him a special schooling adapted to each of the stages of the child [30].

Childhood autism is a disorder that defines the rhythm of life of the person who suffers it and modifies the routine of the whole family; It is a matter of adapting to each of the activities or habits that the child follows so as not to bother him too much, remember that the autistic child will always seek isolation, the idea is that you can adapt your home so that he feels more secure and that environment is become a true home [31].

\section{Related Diseases and Disorders}

The autism rate is estimated at 20 - 60 cases per 10,000 children (Petermann, Niebank \& Scheithauer, 2004). Boys are three or four times more likely to be affected than girls [32]. Data on autism incidence in the United States indicates an increase in the number of cases diagnosed (Fonnbonne, 2003b; Wing \& Potter, 2002). This leap is explained by an increase in autism sensitivity among the population and better diagnostic criteria - the fact is that the number of diagnosed other disorders such as schizophrenia and hyperactivity is at the expense of autism (Shattuck, 2006).75\% to 50\% of children diagnosed with autism exhibit Intellectual Disabilities and 30\% develop epilepsy (Volkmar, 1998), which confirms the suspicions that the cause of autism is organic or genetic. Separate studies have identified cerebral cortex and cerebellum abnormalities as well as elevated serotonin levels in the blood, but these results are small-person studies where it is not clear whether dysfunctions are a cause, consequence or concomitant feature of autism (Poustka, 1998).

\section{Etiology}

There are a variety of theories about the etiology of autism, some of which are supported by significant findings. It is thought that the cause of autism is genetic (Szatmari et al., 1998), but the exact mechanism of gene damage is unclear. Anomalies in pre- and peri- natal development of the child, such as oxygen deficiency at birth, are more a consequence of the genetic anomalies of autistic children, not a cause of autism. Although Canner (1943) considers autism as genetically conditioned, the underlying concepts of the causes of the disorder over the coming 
decades focus on psychoanalytic concepts that autism is caused by an ambiguous - caring attitude but inherently cold - maternal attitude towards the child. In support of this hypothesis, empirical evidence has not been collected, and attempts to treat children with more caressing or paying attention or even being separated from parents do not have a positive effect.

Biochemist Catherine Reid of San Francisco, based on neurobiological research and own experience, believes that some of the nervous system disorders, such as autism, could potentially be linked to the imbalance in the use of sodium glutamate [34].

\section{Interventions}

Successful interventions are focused on behavioral techniques (see Lovaas, TEACCH), and their important characteristic is that they are not entirely focused on the child but also affect their environment, which teaches how to cope with the autistic childhood quirks. Therapy that successfully treats the three main symptoms is not yet known (Howlin, 1998).

\section{Common Symptoms of This Type of Disorder}

Although each child has autism symptoms, he or she has a pattern and patterns, but the following are the most common symptoms of this type of disorder [35]:

\section{1- Social skills}

He does not respond to the call of his name

Do not have more direct visual contact

It often seems that he does not hear an updater

He refuses to hug or shrink on himself

He does not seem to understand the feelings and feelings of others

He seems to like to play alone, expecting his own person in his world.

2- Language skills

Speech begins at a later age, compared to other children

He loses the ability to speak certain words or sentences he previously knew

He maintains a visual connection when he wants something

Speaking in a strange voice or in different tones and rhythms, speaking with a lyrical, terry or robot-like sound,

Can not initiate a conversation or continue a conversation

He may repeat words, phrases or terms, but he does not know how to use them.

\section{Behavior}

Performs repetitive movements such as vibrating, spinning circles or waving hands

He develops habits and rituals that he always repeats

He loses his skill when any change, even the simplest or smallest, changes in these customs or rituals

Permanent movement

He gets stunned and dazzled by certain parts of the objects, such as a wheel in a toy car

Too sensitive, too much, to light, sound or touch, but unable to feel pain.

Young children have difficulties when asked to share their experiences with others. When reading a story, for example, they can not point their finger at the pictures in the book.

This social skill, which develops at a very young age, is essential for the development of language and social skills at a later stage of growth.

As children grow into adulthood, some of them may become more capable and willing to mix and integrate into the surrounding social environment, and they may exhibit behavioral disorders that are less than those that characterize autism, and some even succeed in living a normal life or lifestyle Close to ordinary and natural. On the other hand, others continue to have difficulties in language skills and in social relationships, so that their attainment only increases their behavioral problems worse and worse.

Department of kids, slow to learn new information and skills. Others enjoy natural intelligence, or even higher 
than ordinary people. These children learn quickly, but they have communication problems, in the application of things they have learned in their daily lives, and in adapting / adapting themselves to changing social situations and situations. A very small proportion of children with autism are autistic intellectuals with unique and exceptional skills, particularly concentrated in a particular area such as art, mathematics or music.

\section{Autism in Jordan}

Autism is an uncommon disorder in Jordan and constitutes permanent suffering for most families, especially those who receive no in-kind or material assistance from the state, not only in terms of intervention, but also in the absence of even contributing to educating families about the autism. Health Ministry sources mentioned that there were no accurate statistics on the number of people with autism in the kingdom. However, other sources estimated that some about 8,000 children may have autism disorder in Jordan. Although there is no official and specific data on the number of autism, they called for a comprehensive national survey to find out the exact numbers of people with autism. Knowing accurate data about the number of people with autism and the places of their living is important to facilitate communication with their families and to provide support and special education services to students with autism. In addition to few official efforts about identifying students with autism in jordan, the autism stigma and low knowledge about the autism's characteristics, are barriers for accurate data of the number of people with autism in Jordan.

Families may keep their children with autism in their homes without receiving any special education services because of stigma from community. Although, there are more day and permanent centers for students with autism, still many of them receive services in centers for intellectual disability, which do not meet the needs appropriately. Although early identification of the children with autism is considered half of the intervention, many children in Jordan are indentified late. Many parents are not aware of autism characteristics in their children. Professor of Pediatrics and Gastroenterology Mohamed Al-Rawashdeh expressed his concern about the increasing number of people diagnosed with autism in Jordan. Also, one of the most obstacles for families is the cost of educating students with autism is "very high". Although, public centers for students with autism are existed, however, the low quality education in public centers makes the families to search for private schools with good education quality for their children with autism. As many students with autism need team of teachers and specialists from different disciplines, this makes the private centers expensive for many families in Jordan.

\section{Counseling needs of the parents of children with autism}

The parents of children with autism face many difficulties to teach and deal with their children in Jordan. Zaarer (2009) discusses in his master's thesis the sources of psychological stresses on parents of children with autism in Jordan. According to Zaarer (2009), the most common source of stress on parents was the parent anxiety on the child's future, then the parent inability to meet the needs of her or his child with autism (financial stress source). Other sources of stresses were the cognitive and psychological difficulties of the child with autism in addition to the family difficulties in raising their child with autism.

Also, Al Aoudah (2014) explores, in her master's thesis, the families problems and counseling needs of families of children with autism in the Kingdom of Saudi Arabia, which is an Arabic country beside and similar in culture to Jordan. Using two scales to evaluate the families problems and counseling needs of families for children with autism, Al Aoudah(2014) indicates that the future problems, the financial difficulties, the emotional problems and the psychological stresses were the most common problems for families. Also, the social, information, and the adaptive needs were the most common needs for families (Al Aoudah, 2014). Based on information by two thesis, Al Aoudah(2014) and Zaarer(2009), it's clearly that the future anxiety about the child of autism, the financial difficulties, and the psychological stresses are the most common needs for the families of children with autism in Jordan and another Arab country.

\section{Conclusions}

Autism is a lifelong neurodevelopment condition. It is characterized by differences in behavior, social interaction, communication, special interests and sensory processing. These differences can present people on the autism spectrum with challenges in how they interact with their environment. To receive a diagnosis of autism, these symptoms need to be evident from childhood and impair the person's daily functioning. This paper has taken a deeper look into autism and gave a general overview about its types, treatment, and diagnosis for the history, present and it future and finally at the end of the paper we described an overview about autism in Jordan

\section{References}

Al Aoudah, Rema. (2014). The Problems of Families with Autism Spectrum Children and Their Counseling Needs from the perspective of Mothers of Mothers in the Kingdom of Saudi Arabia (Master Thesis). Retrieved from 
https://theses.ju.edu.jo/Original_Abstract/JUA0763079.pdf

American Psychiatric Association. Diagnostic and Statistical Manual of Mental Disorders (4th ed.). Arlington, VA: American Psychiatric Publishing, Inc; 2000. pp. 69-84.

American Psychiatric Association. Diagnostic and statistical manual of mental disorders. Revised 3rd ed. Washington (DC): American Psychiatric Association; 1987.

Benson, P. R. (2018). The impact of child and family stressors on the self-rated health of mothers of children with autism spectrum disorder: Associations with depressed mood over a 12-year period. Autism, 22(4), 489-501.

Broder Fingert, S., Carter, A., Pierce, K., Stone, W. L., Wetherby, A., Scheldrick, C., ... \& Feinberg, E. (2018). Implementing systems-based innovations to improve access to early screening, diagnosis, and treatment services for children with autism spectrum disorder: An Autism Spectrum Disorder Pediatric, Early Detection, Engagement, and Services network study. Autism, 1362361318766238.

Campbell, K., Carpenter, K. L., Hashemi, J., Espinosa, S., Marsan, S., Borg, J. S., ... \& Tepper, M. (2018). Computer vision analysis captures atypical attention in toddlers with autism. Autism, 1362361318766247.

Choque Olsson, N., Rautio, D., Asztalos, J., Stoetzer, U., \& Bölte, S. (2016). Social skills group training in highfunctioning autism: A qualitative responder study. Autism, 20(8), 995-1010.

Croen, L. A., Zerbo, O., Qian, Y., Massolo, M. L., Rich, S., Sidney, S., \& Kripke, C. (2015). The health status of adults on the autism spectrum. Autism, 19(7), 814-823.

De Rubeis, S., He, X., Goldberg, A. P., Poultney, C. S., Samocha, K., Cicek, A. E., ... Singh, T. (2014). Synaptic, transcriptional and chromatin genes disrupted in autism. Nature, 515(7526), 209.

Fairthorne, J., Jacoby, P., Bourke, J., de Klerk, N., \& Leonard, H. (2016). Onset of maternal psychiatric disorders after the birth of a child with autism spectrum disorder: A retrospective cohort study. Autism, 20(1), 37-44.

Fitzgerald, M., \& Corvin, A. (2001). Diagnosis and differential diagnosis of Asperger syndrome. Advances in Psychiatric Treatment, 7, 310-318.

Fombonne E. (2003b). The prevalence of autism. Journal of American Medical Association, 289, 87-9.

Fombonne, E. (2003a). Modern views of autism. Canadian Journal of Psychiatry, 48, 503-5.

Ghaziuddin, M., Ghaziuddin, N., \& Greden, J. (2002). Depression in persons with autism: implications for research and clinical care. J Autism Dev Disord, 32, 299-306.

Gillberg, C. (1991). Outcome in autism and autistic-like conditions. J Am Acad Child Adolesc Psychiatry, 30, 37582.

Green, J., Pickles, A., Pasco, G., Bedford, R., Wan, M. W., Elsabbagh, M., ... Charman, T. (2017). Randomised trial of a parent-mediated intervention for infants at high risk for autism: longitudinal outcomes to age 3 years. Journal of Child Psychology and Psychiatry, 58(12), 1330-1340.

Hickey, A., Crabtree, J., \& Stott, J. (2018). 'Suddenly the first fifty years of my life made sense': Experiences of older people with autism. Autism, 22(3), 357-367.

Howlin, P. (1998). Practitioner review: Psychological and educational treatments for autism. Journal of Child Psychology and Psychiatry, 39, 307-322.

Hviid, A., Stellfeld, M., Wohlfahrt, J., \& Melbye, M. (2003). Association between thimerosal-containing vaccine and autism. JAMA, 290, 1763-6.

Jamain, S., Quach, H., Betancur, C., Råstam, M., Colineaux, C., Gillberg, I. C., ... Bourgeron, T. (2003). Mutations of the X-linked genes encoding neuroligins NLGN3 and NLGN4 are associated with autism. Nature genetics, 34(1), 27.

Khuntia, A. T. (2018). Identification of Neural Markers for Autism Spectral Disorder (Doctoral dissertation, Indian Institute of Science Education and Research Kolkata).

Lai, M. C., Lombardo, M. V., Auyeung, B., Chakrabarti, B., \& Baron-Cohen, S. (2015). Sex/gender differences and autism: setting the scene for future research. Journal of the American Academy of Child \& Adolescent Psychiatry, 54(1), 11-24.

Madsen, K. M., Lauritsen, M. B., Pedersen, C. B., Thorsen, P., Plesner, A. M., \& Andersen, P. H. et al. (2003). Thimerosal and the occurrence of autism: Negative ecological evidence from Danish population-based data. Pediatrics, 112, 604-6. 
Mayes, S. D., Calhoun, S. L., Waschbusch, D. A., Lockridge, R., \& Baweja, R. (2016). 1.36 AUTISM AND REACTIVE ATTACHMENT/DISINHIBITED SOCIAL ENGAGEMENT DISORDERS: COOCCURRENCE AND DIFFERENTIATION. Journal of the American Academy of Child \& Adolescent Psychiatry, 55(10), S111.

Muskat, B., Burnham Riosa, P., Nicholas, D. B., Roberts, W., Stoddart, K. P., \& Zwaigenbaum, L. (2015). Autism comes to the hospital: The experiences of patients with autism spectrum disorder, their parents and healthcare providers at two Canadian paediatric hospitals. Autism, 19(4), 482-490.

Petermann, F., Niebank, K., \& Scheithauer, H. (2004). Entwicklungswissenschaften. Entwicklungspsychologie, Genetik, Neuropsychologie. Berlin: Springer Verlag.

Poustka, F. (1998). Neurobiology of autism. In Volkmar, F. (Edt.), Autism and pervasive development disorders (pp. 130-168). Cambridge: Cambridge University Press.

Rubenstein, E., Wiggins, L. D., Schieve, L. A., Bradley, C., DiGuiseppi, C., Moody, E., ... Pence, B. W. (2018). Associations between parental broader autism phenotype and child autism spectrum disorder phenotype in the Study to Explore Early Development. Autism, 1362361317753563.

Russell, A. J., Murphy, C. M., Wilson, E., Gillan, N., Brown, C., Robertson, D. M., ... McAlonan, G. M. (2016). The mental health of individuals referred for assessment of autism spectrum disorder in adulthood: a clinic report. Autism, 20(5), 623-627.

Scottish Intercollegiate Guidelines Network (SIGN) 98. Assessment, diagnosis and clinical intervention for children and young people with autism spectrum disorders. A nation clinical guideline. Retrieved from http://www.sign.ac.uk/pdf/sign98.pdf

Shattuck, P. T. (2006). The contribution of diagnostic substitution to the growing administrative prevalence of autism in US special education. Pediatrics, 117, 1028-37.

Szatmari, P., Jones, M. B., Zwaigenbaum, L., \& McLean, J. E. (1998). Genetics of autism. Overview and new directions. Journal of Autism and Developmental Disorders, 28, 351-368.

Taylor, B., Miller, E., Farrington, C. P., Petropoulos, M. C., \& Favot-Mayaud, I. Li. J. (1999). Autism and measles, mumps, and rubella vaccine: no epidemiological evidence for a causal association. Lancet, 353, 2026-9.

Volkmar, F. (1998). Autism and pervasive development disorders. Cambridge: Cambridge University Press.

Wing, L. \& Potter, D. (2002). The epidemiology of autistic spectrum disorders: is the prevalence rising? Mental Retardation and Developmental Disabilities Research Reviews, 8, 151-61.

World Health Organization. International Statistical Classification of Diseases and Related Health Problems, 10th Revision. World Health Organization. $\quad$ Retrieved from http://www.who.int/classifications/apps/icd/icd $10^{\circ}$ nline/

Yi, F., Danko, T., Botelho, S. C., Patzke, C., Pak, C., Wernig, M., \& Südhof, T. C. (2016). Autism-associated SHANK3 haploinsufficiency causes I h channelopathy in human neurons. Science, 352(6286), aaf2669.

Zaarer, Ali. (2009). Psychological Stress Sources among Parents of Autistic Children in Jordan and Styles of Coping with them in Relation to some Variables (Master's Thesis). Retrieved from https://theses.ju.edu.jo/Original_Abstract/JUA0680048.pdf

\section{Copyrights}

Copyright for this article is retained by the author(s), with first publication rights granted to the journal.

This is an open-access article distributed under the terms and conditions of the Creative Commons Attribution license (http://creativecommons.org/licenses/by/4.0/). 